Fifth International Conference on Sustainable Construction Materials and

Technologies. http://www.claisse.info/Proceedings.htm

\title{
DEVELOPMENT OF A PREDICTION SYSTEM FOR THE INITIATION OF SPALLING OF COVER CONCRETE BASED ON VISUAL CLUES FOR REINFORCED CONCRETE BRIDGES IN SERVICE
}

\author{
Takuma KADONO $^{\text {la }}$, Shuntaro TODOROKI ${ }^{1 \mathrm{~b}}$, and Toshiya TADOKORO ${ }^{1 \mathrm{c}}$ \\ ${ }^{1}$ Concrete structures, Structures Technology Division, Railway Technical Research \\ Institute-2-8-38, Hikari-cho, Kokubunji-shi, Tokyo, 185-8540, Japan \\ ${ }^{1 a}$ Email:<kadono.takuma.52@rtri.or.jp>,1bEmail<todoroki.shuntaro.73@rtri.or.jp> \\ , ${ }^{1 c}$ Email:<tadokoro.toshiya.07@rtri.or.jp>
}

\begin{abstract}
Authors have proposed a method that predicts the initiation of spalling of cover concrete by steel corrosion in order to maintain reinforced concrete (RC) structures in service more efficiency. The method is characterized by using steel corrosion rate that is evaluated based on visual clues on the surface of RC structures. In the method, informations: e.g. cover concrete depths and a prediction area of spalling on the environment of steel corrosion, are important.

This research shows that under the method proposed, it is possible to predict spalling of cover concrete demarcating the area into the insolation area and wet surface area of $\mathrm{RC}$ structures, and evaluating cover concrete depths at limited measurement points. Based on these results verified, we have developed spalling-off prediction system based on visual clues, using mobile tablet devices introduced to the field in recent years.
\end{abstract}

Keywords: RC in service, steel corrosion rate, prediction of spalling, visual clues, cover concrete

\section{INTRODUCTION}

It is important in sustainable development to tackle the life prolongation of RC in service based on the evaluation of their future performance. To this end, the engineers engaged in maintenance have to conduct the narrow scrutiny of enormous stocks and to evaluate their soundness quantitatively. In Japan, it is needed to devise more efficient evaluation methods because the engineers engaged in maintenance are decreasing by the declining birth rate and the aging population. When we see the situation with a focus on the cracks and spalling of cover concrete by steel corrosion, it is understood that the steel corrosion rate is on the environment of steel exposure and the cover concrete depth of steel. In order to predict the cracks and spalling of cover concrete appropriately, we should evaluate these factors appropriately.

Authors have proposed a prediction method under which the steel corrosion depth is used as the index. Concretely, using the measurement results of carbonation depths, 
chloride-ion concentration and cover concrete depths, we evaluate the steel corrosion rate based on the spalling area obtained from visual clues (method proposed).

Under the method proposed, it is possible to evaluate the steel corrosion rate affected by such factors as materials, construction and environment, and we do not need the chipping work of concrete for evaluation of steel corrosion rate. It is needed to improve predictive precision and operability, when we consider to apply it in the field of maintenance.

In this research, we have showed that under the method proposed, it is possible to predict spalling of cover concrete demarcating the area into the insolation area and wet surface area of RC structures, and evaluating cover concrete depths by means limited measurement points, based on the investigation results of a deteriorated RC box culvert 40 years of age by affected carbonation and initially-induced chlorides. Furthermore, in order to apply the method proposed to the field of maintenance, we have developed a prediction system based on the method proposed by means of mobile tablet devices which have been introduced in the field in recent years.

\section{DEVELOPMENT OF A PREDICTION SYSTEM}

\section{Prediction Method for Spalling of Cover Concrete Based on Visual Clues}

The method proposed ${ }^{2)}$ predicts the initiation of spalling of cover concrete by using evaluated steel corrosion rate for RC structures in service. Steel corrosion rate is evaluated based on comparison between ratio of spalling area to a target area gotten by visual investigation and by prediction. Figure 1 shows the flow of prediction according to the method proposed. Figure 2 shows the work process of prediction by using the method proposed. First of all, the target area for calculating ratio so that the environment for steel corrosion within the area is the same of spalling area is defined based on the steel corrosion environment. Next, the ratio of spalling is calculated using the spalling area in the meshes with about $50 \mathrm{~mm}$ sides set up on the steel based on visual investigation $\left(R_{\mathrm{sp}}{ }^{\mathrm{vis}}\right)$. It is allowed to consider that the meshes are small $\mathrm{RC}$ specimens. Therefore, the initiation ratio of spalling is calculated according to the prediction result of every mesh using the prediction model shown in Figure 1 (b) $\left(R_{\mathrm{sp}}{ }^{\mathrm{pre}}\right)$. At the time, the meshes give necessary information for prediction, concretely, the measurement results of carbonation depths, chloride-ion concentration and cover concrete depths. Finally, the steel corrosion rate is evaluated in such a way that $R_{\mathrm{sp}}{ }^{\text {pre }}$ accords with $R_{\mathrm{sp}}{ }^{\mathrm{vis}}$. It is possible to predict the initiation of spalling by using the steel corrosion rate for arbitrary age. The method proposed has outstanding features in that it enables us to predict the initiation of spalling based on the steel corrosion rate influenced by such factors as materials, construction and environment, only by means of visual investigation, carbonation depth measurement, cover concrete depth measurement and chloride-ion concentration analysis which are generally conducted at the time of conventional narrow scrutiny and without recourse to the chipping work of concrete to be done in order to get acquainted with the steel corrosion rate.

The prediction model that we used in this research is a deterioration model on the assumption that it is affected by carbonation and initially-induced chlorides according to the "Maintenance Standards for Railway Structures (for concrete structures, Japan)" 
(The Maintenance Stan Investigation n in Figure 1(b). In the Maintenance Standard,
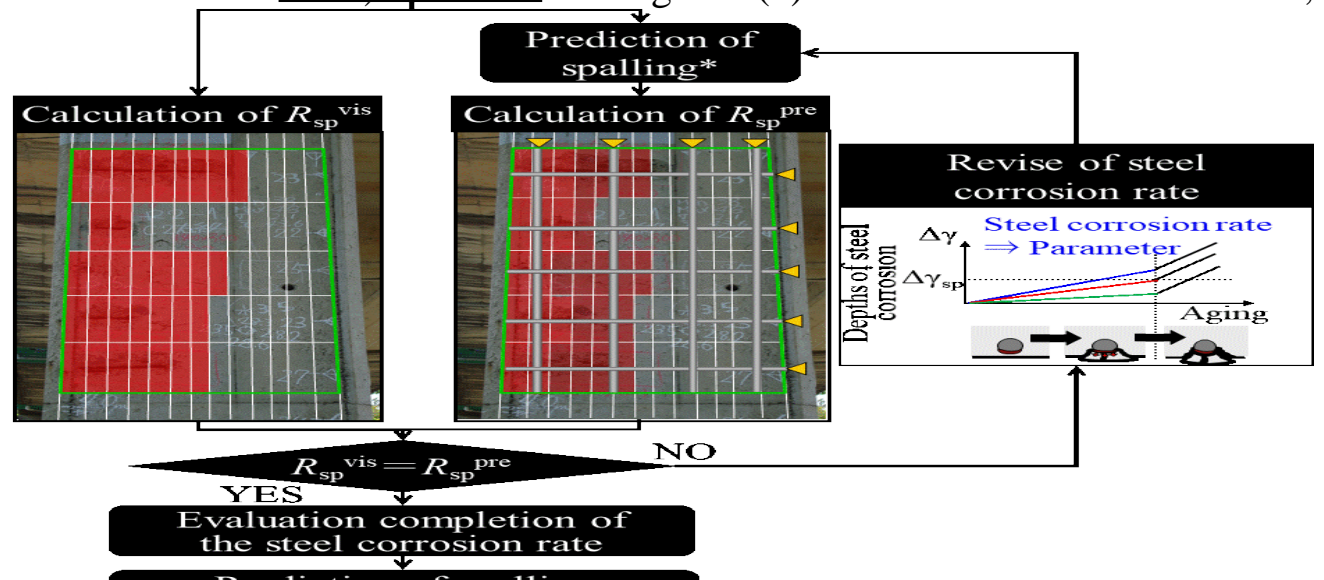

Prediction of spalling

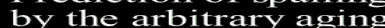

$R_{\mathrm{sp}}$ vis : Initiation ratio of spalling by visual investigation.

$R_{\mathrm{sp}}{ }^{\text {pre }}$ : Initiation ratio of spalling by prediction of spalling.

* : Using the deterioration model by shown in The Maintenance

Standards. However, steel corrosion rate is parameter.

(a) Flow of a prediction

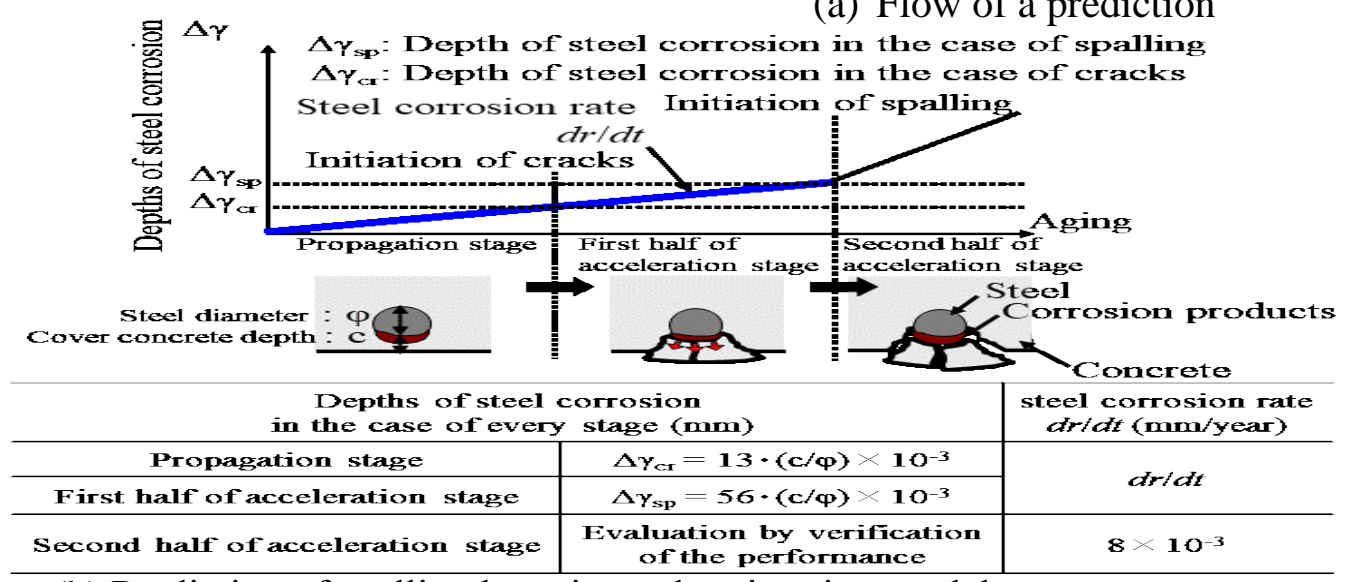

(b) Prediction of spalling by using a deterioration model

Figure 1. Flow of prediction according to the method proposed

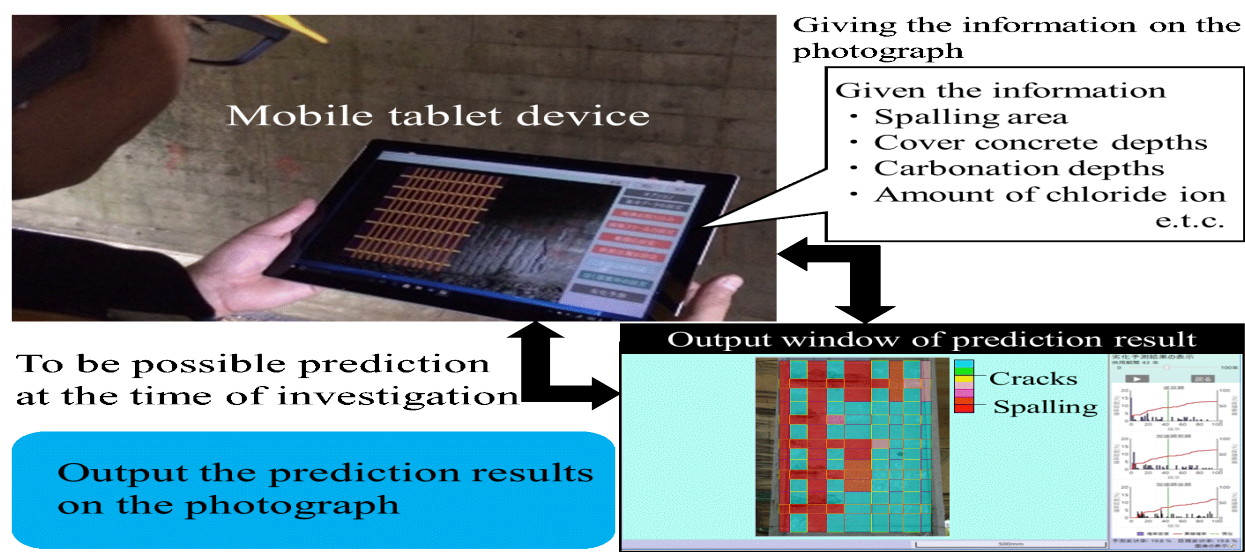

Figure 3. Prediction system developed 
steel corrosion rate is $0 \mathrm{~mm} /$ year in initiation stage in this figure when carbonation remainder depth is $25 \mathrm{~mm}$ or less and amount of initially-induced chlorides is $0.6 \mathrm{~kg} / \mathrm{m}^{3}$ or less. However, we evaluate the steel corrosion rate on the assumption that the deterioration model dose not depend on carbonation depths, and therefore we assume that the steel corrosion rate is invariable until the initiation of spalling.

\section{Development of A Prediction System By The Mobile Tablet Device}

The prediction by means of the method proposed has to be made through the process shown in Figure 2 using the results obtained from the environmental narrow scrutiny. The burden on the engineer will increase by using this process. This process must operate in the office based on the information of investigation memos and pictures after narrow scrutiny. It is needed to predict the initiation of spalling of cover concrete in the future for each environment of steel, because steel corrosion environment is different even in the same member according to wet condition. And, it is needed to get information about cover concrete depths measured as closely as possible, because cover concrete depth is a very important factor in the method proposed and affects the precision $^{3)}$. In the field, this process has to be repeated several times for predicting the initiation of spalling of cover concrete.

Therefore, we have developed a prediction system by the mobile tablet devices. Figure 3 shows the system developed for the prediction, it is possible to input the information about carbonation depths, cover concrete depths, calculation area and so on at the time of investigation by means of the mobile tablet device. By using the tablet device, if it can be possible to predict the initiation of spalling of cover concrete more easy and more accurately that all cover concrete depths can be evaluating from the cover concrete depths measured at the limited points and setting the calculation area according to steel corrosion environment become possible. In the later chapters, we
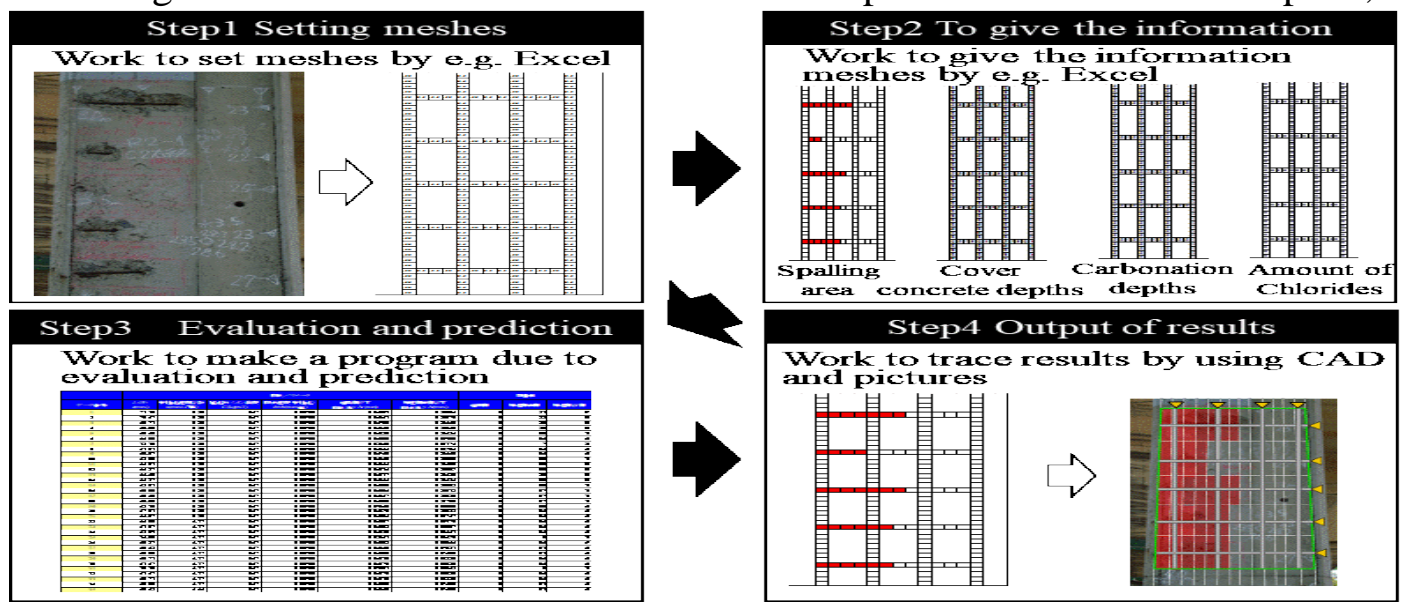

Figure 2. Work process of prediction by using the method proposed

verify the effect on predicting results of using evaluating cover concrete depths and setting calculating area according to steel corrosion environment based on investigation results. 


\section{OUTLINE OF THE INVESTIGATION}

\section{Outline of Targeted for Investigation}

The investigated target is the inner side of a RC box culvert constructed in 1972. The age at the time of the investigation was 45 years. The inner size of a $\mathrm{RC}$ box culvert is $2.0 \mathrm{~m}$ wide and $2.6 \mathrm{~m}$ high and that is used as a road and railways lines pass $2.33 \mathrm{~m}$ above its upper slab. Figure 4 shows the general shape of the targeted structure. Figure 5 shows the detail of the steel placement at the inner side of the RC box culvert shown in the design book. In addition, the measurement positions of carbonation depths is shown in Figure5, chlorides and cover concrete depths. Longitudinal steels and transverse steels are deformed bar (D16). The spacing of the longitudinal steels is $300 \mathrm{~mm}$ and the transverse steels is $500 \mathrm{~mm}$. The design compressive strength of concrete is $24 \mathrm{~N} / \mathrm{mm}^{2}$ and the water-cement ratio is $59 \%$ according to the design book. However, there are not records of construction. In this research, we selected as the research target the inner side from steel No.4 to steel No.28 as shown in Figure5.

Figure 6 shows the neighbor situation of the targeted structure. There is a mountain on the left side facing the starting point. On the right side facing the starting point, there are fields, roads and a river. However there are not any buildings shutting out the sunlight. The influence of air-born chloride is small, because the targeted structure is located in a mountainous area and is more than $1 \mathrm{~km}$ away from the shoreline. The daily mean temperature is $16.9^{\circ} \mathrm{C}$ and the annual mean rainfall is $1,735.3 \mathrm{~mm}$ according to the statistical records for the past 30 years taken nearby the targeted structure by Japan Meteorological Agency.

In the past, defected members by occured cracks and spalling of cover concrete by steel corrosion were repaired by using polymer cement mortar. This cause of steel corrosion is carbonation and initially-induced chlorides, because initially-induced chlorides are included at a density of $1.2 \mathrm{~kg} / \mathrm{m}^{3} \sim 1.7 \mathrm{~kg} / \mathrm{m}^{3}$ (the number of data: 2) and carbonation depths are $31 \mathrm{~mm} \sim 62 \mathrm{~mm}$ (the number of data: 8). Initially-induced chlorides are chlorides mixed with sea sands at the time of mixing.

\section{METHODS AND RESULTS OF THE INVESTIGATION}

\section{Carbonation Depths}

Carbonation depths were measured using the drill method as shown in the Maintenance Standards. Measurement points were located at a height of about $1.2 \mathrm{~m}$ from the ground level and measurement interval was $1.2 \mathrm{~m}$ in the longitudinal direction of the RC box culvert (Figure5). Also, carbonation depths were measured by spraying $1 \%$ solution of phenolphthalein at the sampling hole of chlorides. Figure 7 shows the results of the measurement of carbonation depths at the inner side at the starting point. In addition, this shows the carbonation depths calculated from the equation of carbonation of the effects of the degree of humidity and the bleeding of concrete ${ }^{4)}$. In calculation, the water-cement ratio was used 59\% for evaluating carbonation depths as shown in the design book. Carbonation depth of steel No.4-7 is $62.3 \mathrm{~mm}$, the largest of all the steels, and it is twice as large as the evaluated carbonation depth. 


\section{Cover concrete depths}

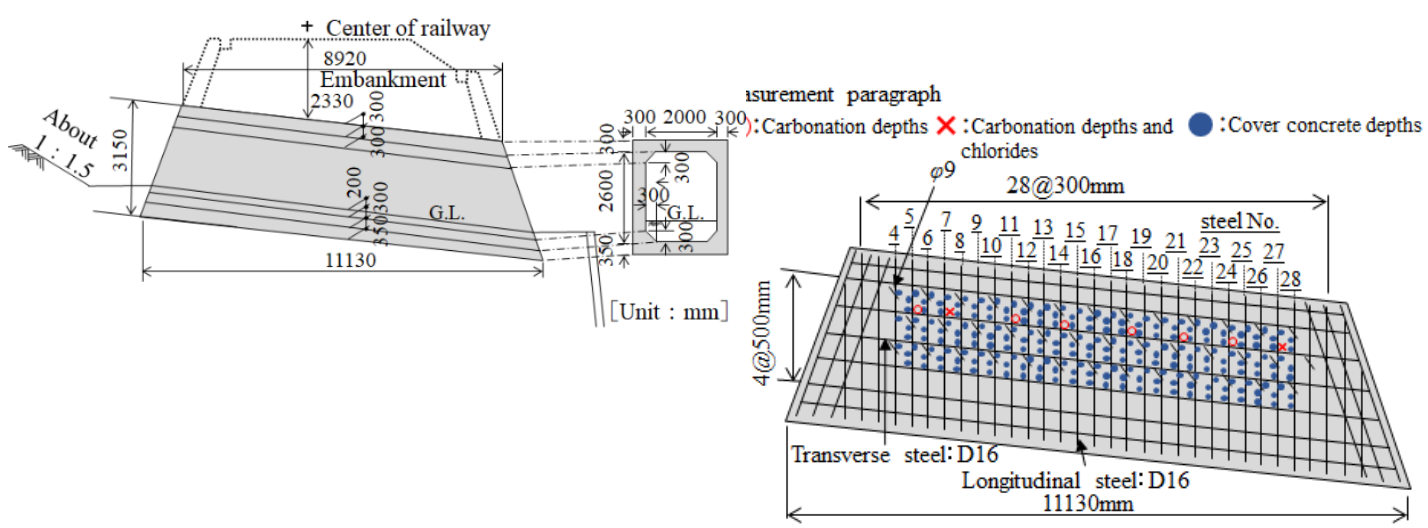

Figure 4. General shape of the targeted structure

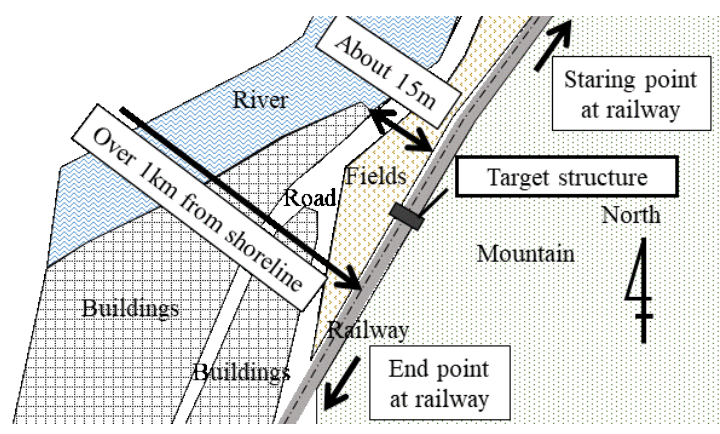

Figure 6. Neighbour situation of the targeted structure
Figure 5. Details of steel placement at the inner side of the RC box culvert shown in the design book

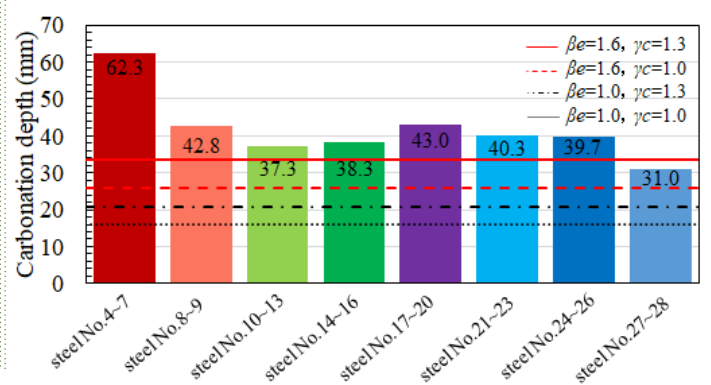

Figure 7. Results of measuring carbonation depths at the inner side 


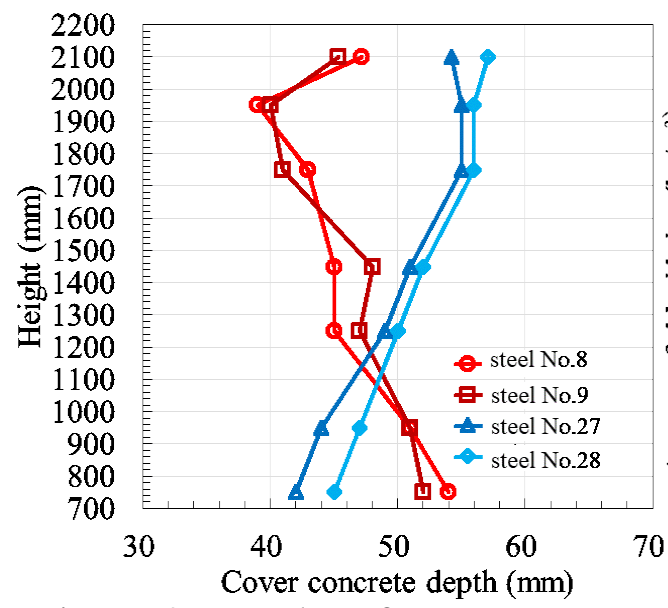

Figure 8. Results of cover concrete depths

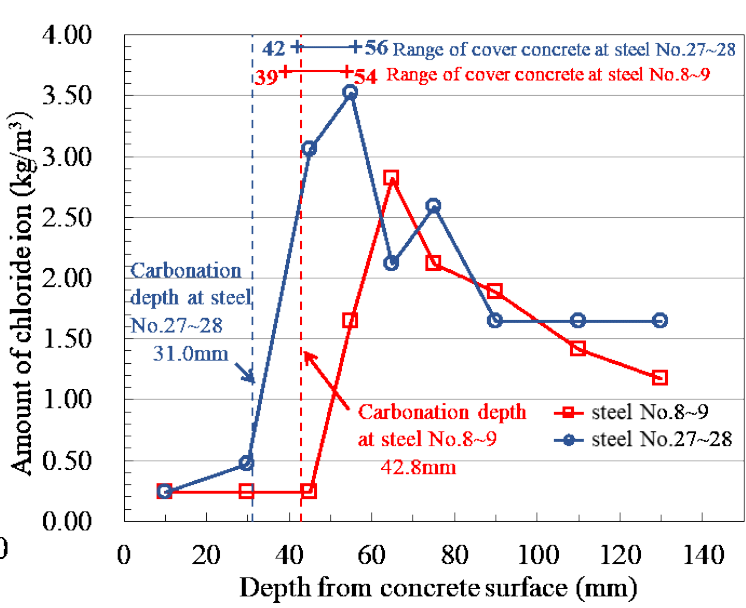

Figure 9. Results of amount of chloride ion

Cover concrete depths were measured using a electromagnetic induction method. Cover concrete depths of the longitudinal steels were measured at two points in the vertical direction between the transverse steels. Cover concrete depths at points except measured points were evaluated by linear interpolation or extrapolation using the measured depths. Figure 8 shows the measurement results of cover concrete depths at steel No.8, 9, 27 and 28 at a point near the measurement location of chlorides.

Cover concrete depths of transverse steels were measured at one point in the horizontal direction between longitudinal steels. Cover concrete depths of except the measurement spots were evaluated by linear interpolation or extrapolation using the measured depths. The cover concrete depth at the intersection point of the longitudinal steel and transverse steel was added $16 \mathrm{~mm}$ from the cover concrete depth of the longitudinal steel, because the longitudinal steels contact with the transverse steels. Regarding the design cover concrete depths, the longitudinal steel is $60 \mathrm{~mm}$ and the transverse steel is $76 \mathrm{~mm}$. The share steel is a circular bar with $9 \mathrm{~mm}$ in diameter like an election steel and they are located at the intersection points at intervals of $600 \mathrm{~mm}$ in the horizontal direction and 500mm in the vertical direction.

\section{Amount of Chloride ion}

The amount of chloride ion was measured by using the potentiometric titration of JIS A 1154 using samples taken by a drill. The samples were taken from two points nearby steel No.8-9 and steel No.27-28 at a height of about 1.2m from the ground level. The surface-to-deep spacing of the measurement was set at $10 \mathrm{~mm}$ or $20 \mathrm{~mm}$ in order to confirm the surface-to-deep distribution of chloride ion. Figure 9 shows the results of the measurement of the amount of chloride ion. In addition, this shows carbonation depths at steel No.8-9 and No.27-28 as shown in Figure 7 and the maximum and minimum values of cover concrete depths. It is reported that the amount of chloride ion is twice as much as that of initially-induced chloride ion at a point 1.8 times the carbonation depth due to carbonation. And the targeted structure shows a similar tendency ${ }^{5), 6)}$. Therefore, the amount of initially-induced chloride was assumed $1.41 \mathrm{~kg} / \mathrm{m}^{3}$ which was the mean value at depth of $120 \mathrm{~mm}-140 \mathrm{~mm}$ from the concrete 
surface.

\section{Investigation by Visual and Hammering}

In the investigation by visual and hammering, we extracted cracks and spalling of cover concrete. In addition, we also decided to extract some information about insolation and wet situation at the concrete surface. Figure 10 shows the information of gotten by visual investigation. According to Figure 10, the area of steel No.4 7 was insolated at the concrete surface, because the area was nearby the edge of the targeted structure. On the other hand, the area of steel No.7 28 was not insolated and darker than the area of steel No.4 7 at the concrete surface. The area of steel No.7 21 was wet situation, compared with the area of steel No.4 7 and No.22 28, because moss grew in the area of steel No.7 21. Therefore, the area at the target inner side was demarcated into three areas based on the investigation obtained from the visual

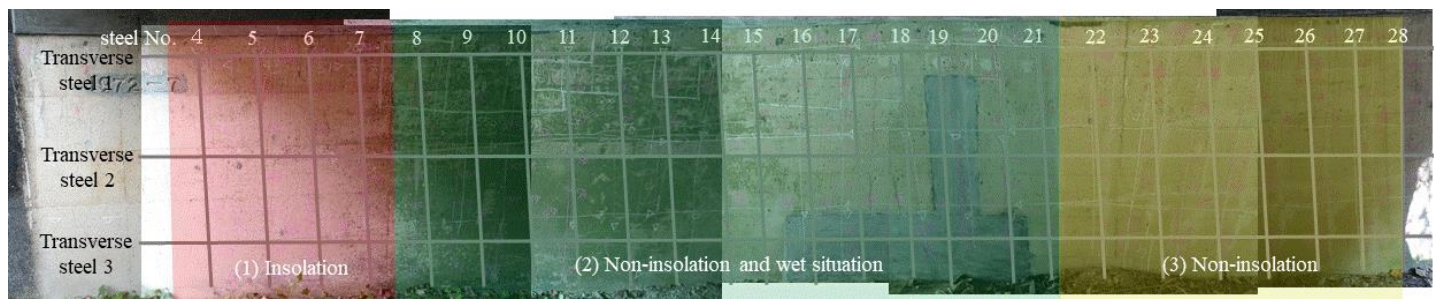

Figure 10. Information of insolation and wet situation at the concrete surface of gotten by visual investigation

investigation as shown in Figure 10.

\section{THE INFLUENCE OF THE SETTING OF THE AREA FOR EVALUATING THE STEEL CORROSION RATE ON THE PREDICTION RESULT}

\section{Outline}

Using the method proposed, it is possible to evaluate the steel corrosion rate including the influence of material, construction and environment. However, it is assumed that the steel corrosion rate differs for each area depending on the degree of supply of water hanging, and repetitive drying and wetting even in the same member although the evaluated steel corrosion rate is averaged in each evaluation area. Therefore, the result of prediction and that of investigation may not match, if we predict the spalling of cover concrete for the entire member. It is important to predict it more accurately by setting the evaluation area for evaluating the steel corrosion based on steel corrosion environment.

In this research, we examine the influence of the setting of evaluation area based on the information about insolation, wet condition and moss growth obtained from visual investigation.

Setting the Area for Evaluation of the Steel Corrosion Rate Based on Visual Clues Figure 11 shows the relationship between the initiation of cracks and spalling of the cover concrete affected by cover concrete depths and carbonation remainder depths, which is defined as cover concrete depth minus carbonation depth at a point nearby the measurement point of cover concrete depth, at the inner side of the targeted 
structure. It is thought that the progress of carbonation causes of the steel corrosion. However, spalling has not occurred at area (1) as shown in Figure 11, although area (1) has smaller carbonation remainder depths than area (2). Therefore, despite of the progress of carbonation, the steels in areas under normal dry condition by insolation like area (1) do not corrode. And, the steels in areas under normal wet condition by flourishing moss and no-insolation like area (2) corrode. Therefore, it is needed to select the evaluation area depending on the degree of dryness or wetness of the concrete surface.

In this research, we try to predict spalling of cover concrete according to the evaluation area demarcation, concretely area (1), area (2) and area (3) based on visual clues as shown in Figure 10.

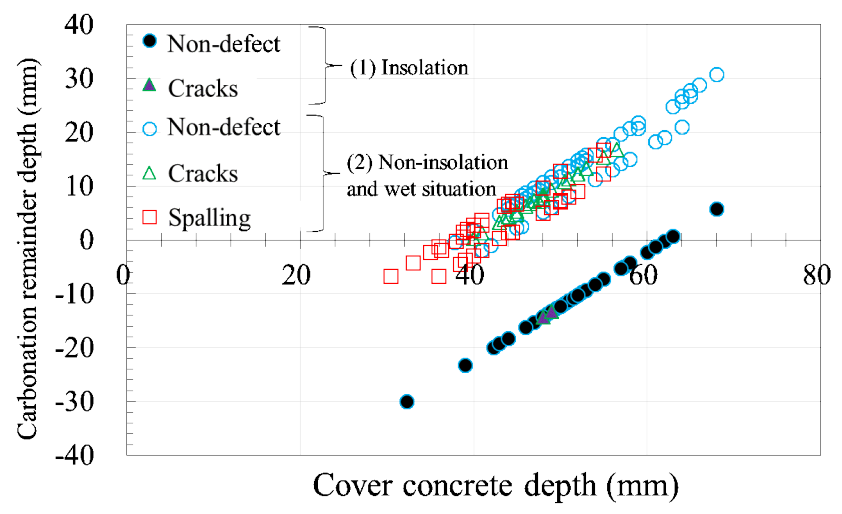

Figure 11. Relationship of initiation of defect affected by cover concrete depths and carbonation remainder depths at the inner side

\section{The Influence on Prediction Results}

We verified the influence of the evaluation areas divided based on visual clues when the prediction of spalling of cover concrete is made according to these areas divided. Figure 12 shows the area of spalling obtained from the investigation. Figure 13 shows the prediction result when the entire inner surface is assumed to be the evaluation area. Figure 14 shows the prediction result when the evaluation areas are demarcated based on visual clues. And we assumed that repaired area is a spalling area.

While $R_{\mathrm{sp}}{ }^{\mathrm{vis}}$ is $15.8 \%, R_{\mathrm{sp}}{ }^{\text {pre }}$ in the case of Figure 13 is $16.2 \%$, and $R_{\mathrm{sp}}{ }^{\text {pre }}$ in the case of Figure 14 is $16.1 \%$. The errors between $R_{\mathrm{sp}}{ }^{\mathrm{pre}}$ and $R_{\mathrm{sp}}{ }^{\mathrm{vis}}$ was within $0.5 \%$ in the cases. We calculate the conformity ratio of meshes by analyzing the match between the spalling meshes shown in Figure 12 and the spalling meshes of prediction. The conformity ratio in the case of Figure 13 is $55.6 \%$, and the conformity ratio in the case of Figure 14 is $57.8 \%$. Regarding the comparison of the occurrence trends of the initiation of spalling, the result shown in Figure 14 simulated the result shown in Figure 12 better than the result shown in Figure 13 simulated the result shown in Figure 12. Therefore, we considered that setting the evaluation area based on visual clues enabled us to simulate the initiation of spalling roughly because the prediction result obtained from this method gave a higher conformity ratio. However, we could not simulate the occurrence trends in the repaired area located down area at steels No.1620. As a reason for this, it is considered that the steel corrosion rate in this area is 


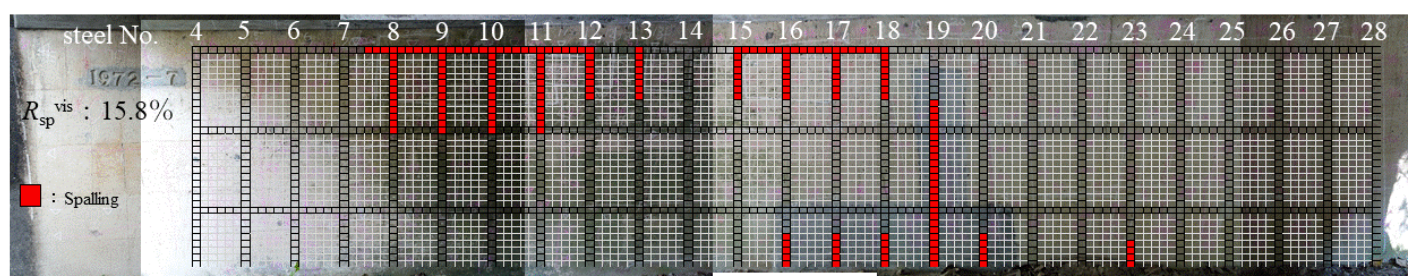

Figure 12. Area of spalling by getting investigation

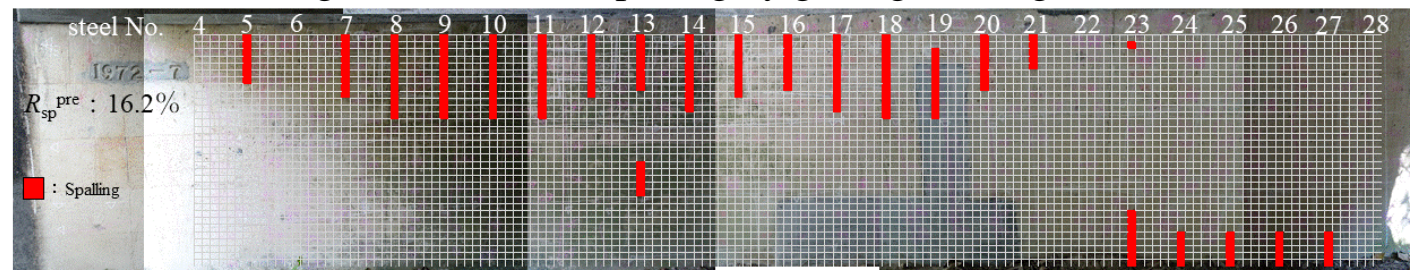

Figure 13. Result by using evaluation area defined entire inner side

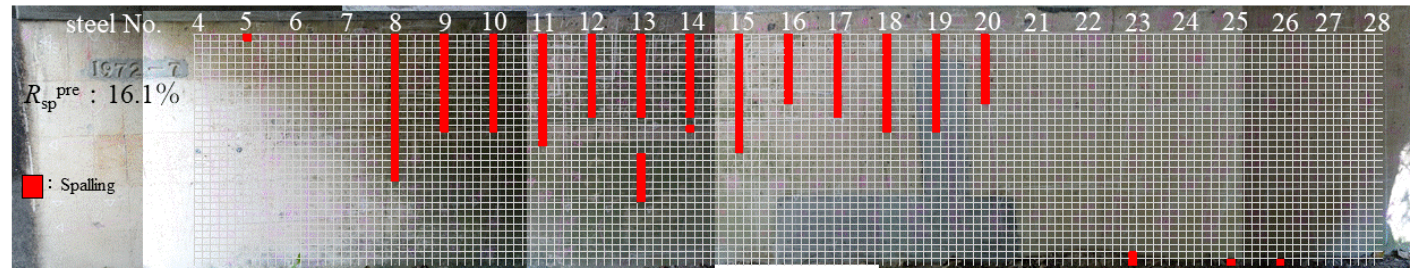

Figure 14. Result by using demarcated the evaluation area based on visual clues

higher than in the upper area due to the effect of water supplied from the ground surface. However, we did not distinguish the environment at the ground surface from that in other areas because the situation where moss flourishes at the concrete surface was not different between the ground surface and the other areas, and carbonation depth was not quite different between the measurement result of $33.7 \mathrm{~mm}$ at a height of $1.2 \mathrm{~m}$ from the ground level and that of $29.1 \mathrm{~mm}$ at a height of $0.5 \mathrm{~m}$ from the ground level. Therefore, setting an area nearby the ground surface based on the environment therein is a future task.

\section{THE INFLUENCE OF MEASURMENT POINTS OF COVER CONCRETE DEPTHS ON PREDICTION RESULTS}

\section{Outline}

The cover concrete, the depth of which is the thickness from the steel surface to the concrete surface, has functions of protecting the steel from corrosive factors and resisting mechanically to the initiation of cracks and spalling of the cover concrete caused by the corrosion expansion pressure of the steel. Therefore, it is needed to input the information as to measured cover concrete depths as minutely as possible, in order to perform the prediction over spalling more accurately. However, it is not easy to measure the cover concrete depths of entire structures even with non-destructive investigation such as electromagnetic induction method for measuring them relatively easily and accurately. In this research, we verified the influence of the evaluation of cover concrete depths of the entire member based on limited measurement points on the prediction result through a comparison with the evaluation of cover concrete depths of the entire member by means of the electromagnetic induction method. 


\section{Evaluation of Cover Concrete Depths in the Entire Member}

Figure 15 shows the process of evaluating the cover concrete depths of the entire member based on measurement at limited points. We evaluate the cover concrete depths of the entire member using the measurement of cover concrete depths of longitudinal steels at 9 points. First, three longitudinal steels are selected from the right edge, left edge and middle of the entire member so as to be one from each of them, and we obtain cover concrete depths at 9 points made of middle, upper and lower points of each of the three longitudinal steels selected. We evaluate the form of the longitudinal steels using a quadratic interpolation equation. Next, we evaluate the form of the transverse steels using a quadratic interpolation equation from the evaluation of 3 cover concrete depths of the longitudinal steels. Finally, we evaluate the form of other steels which are not the steels already selected using a primary equation by means of the least squares method based on the evaluation of the cover concrete depths of the transverse steels. This evaluation method is base on a concept that longitudinal steels and transverse steels are not independent, and they form an integral shape. In this research, we selected 3 points in steel No.4, 15 and 28 as shown in Figure 5, and we
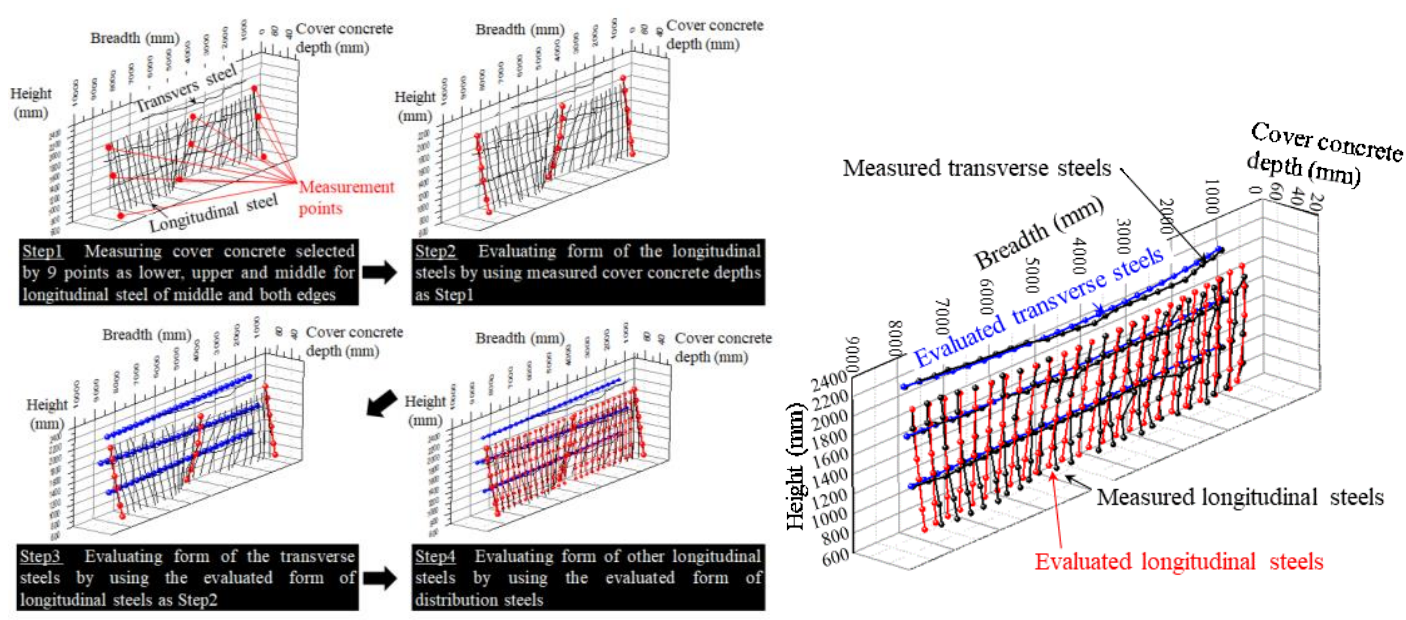

Figure 15. Process of evaluating the

Figure 16. 3 dimensional distribution cover concrete depths based on limited of cover concrete depths measurement points

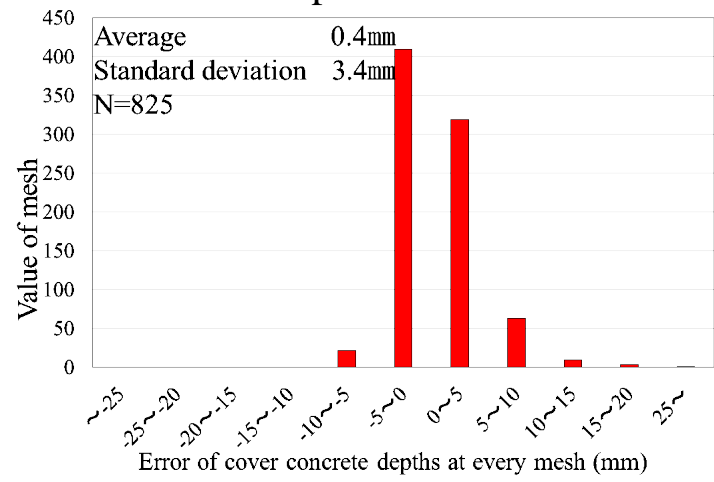

Figure 17. The errors in the evaluation of cover concrete depths

(Longitudinal steel)

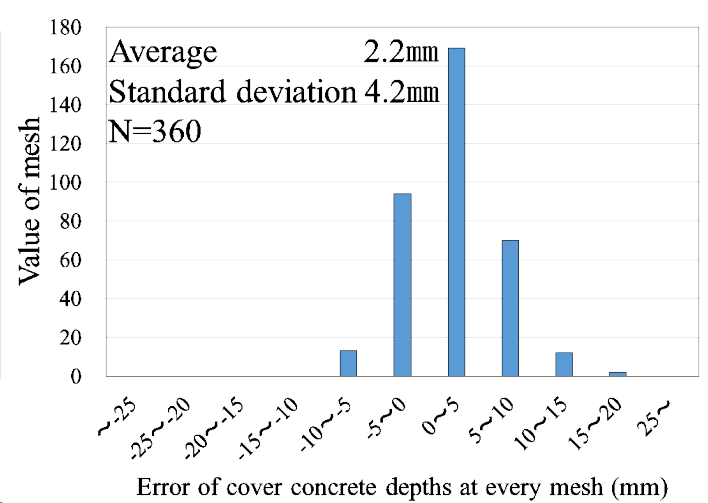

Figure 18. The errors in the evaluation of cover concrete depths (Transverse steel)

evaluate the cover concrete depths of the entire member based on the measurement at 
limited points as shown in Figure 15. The interval of points where the cover concrete depth is evaluated is set at approximately $50 \mathrm{~mm}$. Figure 16 shows the 3 dimensional distribution of cover concrete depths. Figure 17 and Figure 18 show the errors in the evaluation of cover concrete depths for the longitudinal steels and transverse steels respectively. The errors shown in these figures are the deviation between the cover concrete depths obtained from the field inspection and those obtained by linear interpolation or extrapolation of the evaluated values based on the same intervals as that used for evaluation of cover concrete depth. The errors of the longitudinal steels is $22 \mathrm{~mm}$ at the most. However, we can evaluate the cover concrete depths with an error of approximately $\pm 10 \mathrm{~mm}$ for both longitudinal steels and transverse steels.

\section{The Influence on Prediction Result}

We verified the influence of the evaluation of cover concrete depths based on measurement at limited points on the prediction result by actually predicting the spalling of cover concrete based on the cover concrete depths evaluated by means of the method proposed. We also verified the influence of the prediction result of the evaluation of cover concrete depths based on measurement at limited points after setting the evaluation area according to the visual investigation of insolation, wet condition and flourishing moss. Figure 19 shows the prediction result obtained from the cover concrete depths evaluated in situation where the entire inner side is the prediction. Figure 20 shows the prediction result obtained from the cover concrete depths evaluated in situation where the evaluation area is demarcated based on visual clues. While $R_{\mathrm{sp}}{ }^{\text {vis }}$ is $15.8 \%, R_{\mathrm{sp}}{ }^{\text {pre }}$ in the case of Figure 19 is $15.8 \%$, and $R_{\mathrm{sp}}$ pre in the case of Figure 20 is $16.2 \%$. The errors between $R_{\mathrm{sp}}{ }^{\text {pre }}$ and $R_{\mathrm{sp}}{ }^{\text {vis }}$ was within $0.5 \%$ in the cases. The conformity ratio in the case of Figure 19 is $39.6 \%$, and the conformity ratio in the case of Figure 20 is $43.3 \%$. We can see that the conformity ratios shown in Figure 19 and Figure 20 are by about $20 \%$ lower than those shown in Figure 13 and Figure 14. This is because the difference in cover concrete depths between the result

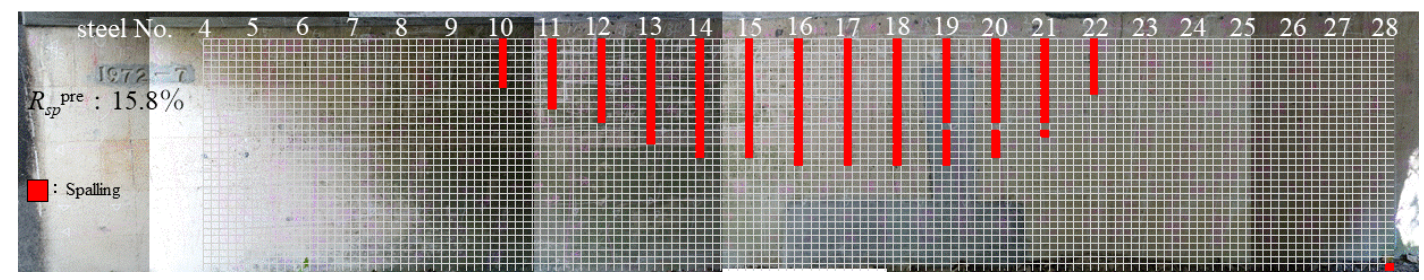

Figure 19. Result of the prediction obtained from cover concrete depths evaluated in situation where the entire inner side is the prediction areas

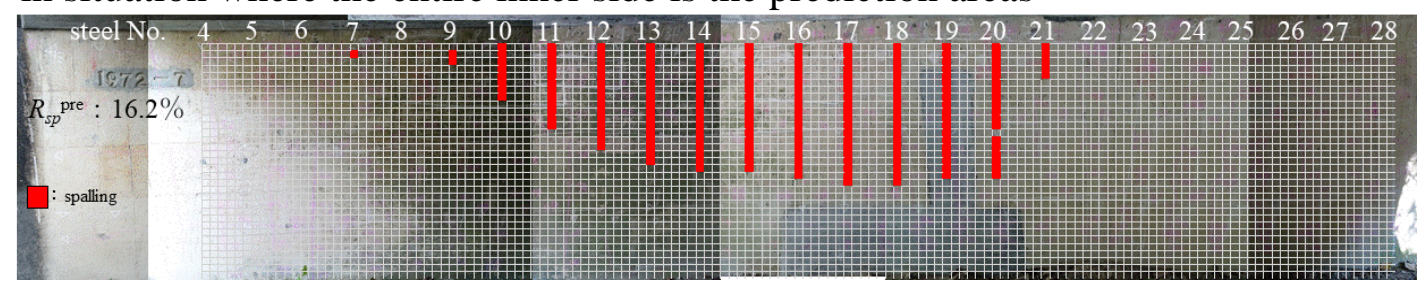

Figure 20. Result of the prediction obtained from evaluated cover concrete depths in situation where demarcated the evaluation areas based on visual clues

obtained from the measurement and that obtained from the evaluation, and we see that using the evaluated cover concrete depths makes the prediction accuracy low. 
However, it is considered that the spalling area is reproduced roughly. In the case of the prediction by means of cover concrete depths evaluated based on measurement at limited points, it is possible to predict the initiation of spalling of cover concrete roughly, but the prediction accuracy is not sufficiently high. We consider that the information obtained from these results is useful when we extract priority investigation areas at the time of the next investigation and select areas where repairs are made by such methods as patching. Therefore, in this research we construct, as a method verified a system for predicting the initiation of spalling of cover concrete by means of evaluated cover concrete depths of the entire member based on measurement at limited points.

\section{CONCLUSIONS}

In this research, we developed a system for predicting the initiation of spalling of cover concrete by means of the method proposed, for which we verified how the prediction accuracy of spalling of cover concrete is affected by setting the evaluation area based on the visual investigation of insolation, wet condition and flourishing moss and evaluating cover concrete depths based on measurement at limited points. The results obtained in this research are shown below.

(1) We developed the system for predicting the initiation of spalling of cover concrete by simple operation at the time of investigation.

(2) Setting the area of evaluating the steel corrosion rate for each environment can improve the accuracy of the prediction.

(3) Using the all cover concrete depths of the member that are evaluated by some cover concrete depths measured at the limited points can predict the initiation of spalling of cover concrete roughly but efficiently.

\section{REFERENCES}

1) Railway Technical Research Institute: Maintenance Standards for Railway Structures(for concrete structures, Japan), pp.222-233, 2007.1

2) S.Todoroki, K.Watanabe, N.Kitoh and Y.Ryu: Study on the Influence of Steel Corrosion by Using the Data of Investigation, Annual reports of Japan Concrete Institute, Vol.37, No.1, pp.920-924, 2015

3) M.Sogabe, Y.Tanimura, H.Matsuhashi and M.Uno: Deterioration Prediction and Defect Investigation of RC Handrails in Railway Viaducts, Concrete engineering of Japan Concrete Institute, Vol.47, No.8, pp.16-24, 2009.8

4) Japan Society of Civil Engineers: Standard Specifications for Concrete Structures2012, pp.145-148, 2012

5) S.Tottori, T.Miyagawa: Deterioration Prediction by the steel corrosion in the case of affected by carbonation and initially-induced chlorides, Journal of Japan Society of Civil Engineers, No.802, V-69, pp.181-196, 2005.11

6) Review Committee of Concrete Structures for Sanyo-Shinkansen: The report of Review Committee of Concrete Structures for Sanyo-Shinkansen,2007.7 
